\title{
Development of a Supplementary Food Capsule From Annona muricata (Soursop)
}

\author{
By
}

Dasanayaka Mudiyanselage Randika Udara Dasanayaka

Thesis submitted in partial fulfillment of the requirement for the degree of Master of Food Science and Technology,

Department of Food Science and Technology,

Faculty of Applied Science,

University of Sri Jayewardenepura, Sri Lanka. 


\section{Declaration}

The work describe in this thesis was carried out by me under the supervision of Prof. Arthur Bamunuarachchi and a report on this has not been submitted in whole or in part to any university or any other institution for another Degree /Deploma.

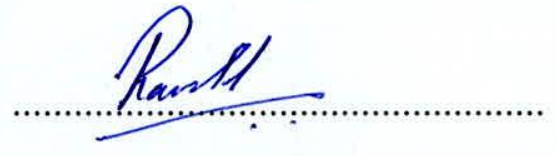

D.M. Randika Udara Dasanayaka

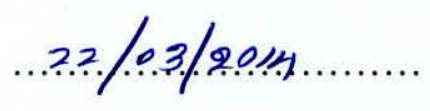

Date 
"I certify that the above statement made by the candidate is true and that thesis is suitable for submission to the university for the purpose of evaluation. "
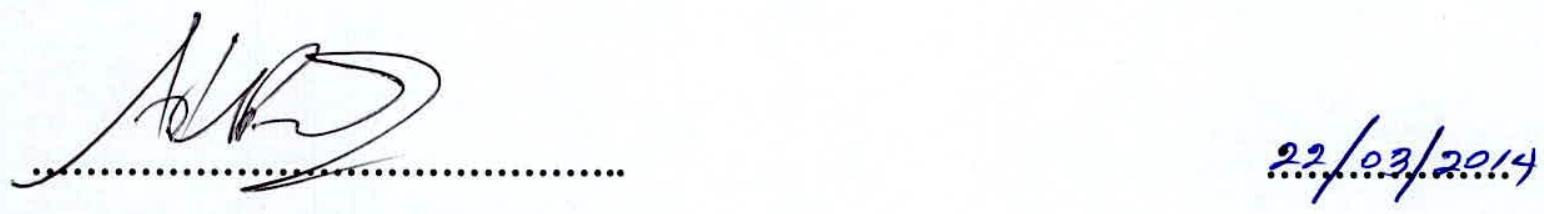

Professor Arthur Bamunuarachchi

\section{Date}

(Emerites Professor, University of Sri Jayewardenepura, Sri Lanka)

\section{Consultant Food Scientist and Technologist,Specialist}

Agri.Business,Post Harvest and Food Processing Trainer

Chief of Group

"ON SITE", Consultancy,Training and Trade Systems. 


\section{Table of Content}

Table of Content $\quad$ i

List of Tables $\quad$ V

List of Figures vi

Acknowledgment vii

Abstract viii

Chapter 1 - Introduction 1

Chapter 2 - Literature review 4

2.1 Occurrence of Non Communicable diseases 4

2.2 Dietary Supplements 6

2.2.1 Benefits of Dietary Supplements 6

2.2.2 Risk of Taking Dietary Supplements 8

2.2.3 More about Herbal food Supplements 8

2.2.4 Standards and Regulations for Herbal Supplements 9

2.3 About Annona muricata (Soursop) 10

2.3.1 Taxonomy and Distribution of Annona muricata 10

2.3.2 A.muricata Fruit Description 11

2.3.3 Distribution of A.muricata 12

2.3.4 Taxanomic Classification of Soursop 12

2.3.5. Uses of Soursop 13

2.3.5.1 Food products and Industrial uses of A. muricata 13

2.3.5.2. Medicinal Uses of A. muricata 14

2.3.5.3 Other Uses 15

2.3.6 Experimental Evidences for Medicinal uses 16

2.3.7 Mode of Action 17

$\begin{array}{ll}\text { 2.3.8 Plant Chemicals } & 17\end{array}$

2.3.9 Phytochemicals of A.muricata 19

2.3.10 Properties of Soursop leaf and Bark 24

2.3.11 Nutritive Profile 25

2.3.12 Contradictions of A.muricata 27 
2.4.1 Determination of Mineral content - Inductively Coupled

Plasma (ICP)method. $\quad 29$

2.4.2 Determination of anticancer properties $\quad 30$

2.4.2.1 Brine Shrimp Assay $\quad 30$

2.4.2.2. Potato Disk Bio Assay 30

2.4.2.2.1 Isolation of Agrobacterium tumerfaicens and Characterization of the Organism 31

2.4.3 Raman Spectrum 33

Chapter 3 - Materials and Method 35

3.1 Identification of A.muricata (Soursop) and Collection of Plant Material 35

3.2 Preparation of Soursop Powder 35

3.2.1 Preparation of Capsules 36

3.2.2. Determination of Yield 36

3.3 Determination of Nutritional quality. $\quad 37$

3.3.1. Determination of Moisture 37

3.3.2. Determination of Total Fat 37

3.3.2. Determination of Crude Protein 38

3.3.3. Determination of Crude Fiber 40

3.3.4. Ash Content 41

3.3.5. Determination of Total Sugar and the Reducing sugar 42

3.3.5.1. Determination of Reducing Sugar $\quad 42$

3.3.5.1.1. Standardization of Fehling solution $\quad 42$

3.3.5.2. Determination of Total Sugar 43

3.3.6. Determination of Vitamin C 44

3.3.7.Determination of Mineral content using Inductively Coupled Plasma Spectrometer (ICP-OES) 45

3.3.7.1. Sample Preparation - Microwave Digestion 45

3.3.7.2. Measurement of Metals Using ICP-OES 45 
3.4. Analysis of Medicinal Value - A.muricata fruit 46

3.4.1. Preparation of Extracts. 46

3.4.2. Phytochemical Analysis 47

3.4.2.1 Alkaloids 47

3.4.2.2 Tannins 48

3.4.2.3 Saponins $\quad 48$

3.4.2.4 Glycosides $\quad 49$

3.4.2.5. Flavonoids $\quad 49$

3.4.2.6 Phenols $\quad 50$

3.4.2.7 Anthroquinones $\quad 50$

3.4.2.8 Steriods 51

3.4.2.9. Anthocyanins 52

3.4.2.10. Leucoanthocyanins 52

3.4.2.11 Coumarins 53

3.4.2.12 Emodins 53

3.4.2. Comparison of Anti cancer properties of Fresh fruit and Capsule (Powder) 53

3.4.3.1 Isolation of Agrobacterium tumerfaciens from Crown gall diseased plant 53

3.4.3.2. The potato Disc Bioassay Modified for plant extracts (A.muricata) 55

3.5 Analysis of Raman spectrums of different extracts. 58

3.6 Analysis of the presence of phytochemicals in the other parts

of the plant - leaf and stem bark $\quad 58$

Chapter 4 - Results and Discussion $\quad 59$

4.1 Identification of Soursop Plant 59

4.2 Preparation of Soursop Powder $\quad 59$

$\begin{array}{ll}4.2 .1 \mathrm{TPC} \text { count } & 61\end{array}$

4.2.2. Yeast and Mould count 62

4.2.3 Coliform count $\quad 62$

4.2.4 Analysis of Color 63

4.2.5. Preparation of Capsules 64 
4.2.6. Determination of Yield 64

4.3 Nutritional Quality of Soursop $\quad 65$

4.3.1 Moisture 65

4.3.2. Nutritional data analysis 66

4.3.2.1 Fat content 66

4.3.2.2. Protein content 66

4.3.2.3 Crude Fiber 67

4.3.2.4 Ash content 68

4.3.2.5 Sugar 68

4.3.2.6. Vitamin C 68

4.3.2.7 Carbohydrates and Total Energy 69

4.3.3. Analysis of Minerals 69

4.3.3.1 Iron $(\mathrm{Fe}) \quad 69$

4.3.3.2 Sodium $(\mathrm{Na}) \quad 69$

4.3.3.3 Calcium $(\mathrm{Ca}) \quad 69$

4.3.3.4 Potassium (K) $\quad 70$

4.3.3.5 Magnesium (Mg) $\quad 70$

4.3.3.6 Phosphorous (P) $\quad 71$

4.4. Determination of Medicinal Value of Fruit powder 71

4.4.1. Phyto Chemical Analysis for fruit 71

4.4.1.1. Anthraquinones 72

4.4.1.2. Flavonoids 72

4.4.1.3 Glycosides $\quad 73$

4.4.1.4 Alkaloids $\quad 73$

4.4.1.5 Emodins, Saponins, leucoanthocyanin and steroids 73

4.4.1.6 Coumarins 73

4.4.1.7 Anthocyanins 73

4.4.1.7 Tannins $\quad 73$

4.4.2 Determination of Anti cancer properties $\quad 74$

4.5 Spectrums of Thermo scientific Analyzer 75

4.6 Phytochemical Analysis for Leaf extract and Stem bark extracts $\quad 78$ 
Chapter 5 - Conclusions

Chapter 6 - Recommendations

Appendix

Appendix A

Appendix B - 1

82

Appendix B - 2 84

Appendix B - 3

Appendix B - 4 88

Appendix B - 5 88

Appendix C 89

References 


\section{List of Tables}

Table 1: cancer Mortality data $1985-2003$

Table 2: Denomnators used for calculation in cancer registry

Table 3: Nutrition composition of A.muricata

Table 4: Functional groups of Raman Spectrum Vs peak wave length

Table 5: Moisture, and Micro parameters at different drying temperatures

Table 6: Moisture determination of raw fruit and powder

Table 7: Nutrition content of Soursop powder

Table 8: Phytochemical analysis of fruit extracts

Table 9: Phytochemical analysis of leaf and Stem bark extracts

Table 10: Table of MPN counts

Table 11: Moisture Analysis

Table 12: Moisture - Batch Dried at $60{ }^{\circ} \mathrm{C}$

Table 13: Moisture - Batch Dried at $50{ }^{\circ} \mathrm{C}$

Table 14: Moisture - Batch Dried at $40{ }^{\circ} \mathrm{C}$

Table 15: Microbiological Counts of Different Batches.

Table 16: Fat Analysis

Table 17: Ash analysis

Table 18: Crude fiber

Table 19: Protein content

Table 20: Reducing sugar content

Table 21: Total sugar content

Table 22: Determination of Energy 


\section{List of Figures}

Figure 1: Schematic diagram of a Soursop plant Andrade, L.R.M. et.al, 2004

Figure 2: Soursop Flower

Figure 3: Soursop Leaves

Figure 4: Soursop Fruit

Figure 5: Examples for Acetogenins

Figure 6: Typical structure of Alkaloids

Figure 7: Common Flevanoids

Figure 8: Structure of Tannin

Figure 9: Caffeic acid and Caffeic acid ethyl ester

Figure 10: Antroquinones

Figure 11: ICP - OES

Figure 12: shows tumor forming ability of selected isolates on potato disc in different stains of $A$. tumerfaiens

Figure 13: Thermo scientific Analyzer (Ahura)

Figure 14: Pea shoot with Crown gall disease

Figure 15: Area is sterilized using burners

Figure 16: Plates showing potato disks

Figure 17: Taxonomic identification of Soursop

Figure 18: Variation of Moisture with drying temperature

Figure 19: Microbial Count in Soursop powder Dried at Different Temperatures

Figure 20: $\mathrm{A}=$ Sample dried at $40{ }^{\circ} \mathrm{C}, \mathrm{B}=$ Sample dried at $50{ }^{\circ} \mathrm{C}, \mathrm{C}=$ Sample dried at $60{ }^{\circ} \mathrm{C}$

Figure 21: Hard gel capsules filled with Soursop powder

Figure 22: Showing a potato disk with crown gall tumor

Figure 23: Water extract of dried fruit - Raman spectrum

Figure 24: Water extract of fresh fruit - Raman spectrum

Figure 25: Ethanol extract of dried fruit - Raman spectrum

Figure 26: Ethanol extract of fresh fruit - Raman spectrum

Figure 27: Methanol extract of dried fruit - Raman spectrum

Figure 28: Methanol extract of fresh fruit - Raman spectrum 


\section{ACKNOWLEDGEMENT}

First and foremost I wish to thank with deepest gratitude to my supervisor, Professor Arthur Bamunuarachchi, Emerites Professor,University of Sri Jayewardenepura, Sri Lanka, for his valuable guidance, encouragement and suggestions given throughout my research project. He has been always behind me from the beginning of the research, till to the last moment, with his valuable comments and supports.

I extend my special thank to prof. K.K.D.S. Ranaweera, for the guidance given to us from the very beginning, by explaining the value of doing research and guiding us at each step of the research. Also I would like to be thankful to Dr. Jagath Wansapala, coordinator of the M.Sc program, Mrs. Rupika perera, assistant coordinator and all the other academic and non academic staff for their encourangement and support through out the project.

Also, I would be grateful to Mr. Kolitha Amarasinghe, manager, chemical section, SGS lanka PVT Itd, and Mr. Amila, technical officer, SGS lanka PVT ltd, for providing facilities to do mineral analysis and also I would like to thank Mr. Sarath Kumara, Laboratory Assistant of Ceylon tea Services PLC, for providing facilities in microbiology analysis.

Also, I am sincerely thankful to all my friends and my mother for their valuable support and encouragement throughout this research. 


\begin{abstract}
Importance of the disease prevention ability of plants, is increasing day by day as the occurrence of non communicable diseases is increased rapidly. Many people think that the consumption of fresh plant parts are the best choice. But due to many reasons it is not feasible for every one.
\end{abstract}

Annona muricata (Soursop) is a plant which is endemic to Latin American countries, and it has been used for many medicinal purposes by locals. Modern scientific studies have also been revealed that A.muricata has many medicinal uses; especially it has the cancer prevention / curing ability due to the presence of special group of chemicals called Annonaceous acetogenins.

In this research, main aim was to produce a supplementary food capsule using Soursop, which has all the critical nutritional and medicinal values as the fresh fruit. Proximate analysis was done to determine the nutritional quality of the product and phytochemical analysis was performed for fresh fruit, dried powder, leaf extract and bark extracts to analyze the medicinal importance. Also as the preliminary in vitro analysis of anticancer properties, potato disc assay was done. Raman spectrums of ethanol, Methanol and water extract of fresh fruit and dried powder was compared to determine the similarities.

Test results have revealed that most of the nutritional factors of fresh Soursop, was similar to that of dried powder with some exceptions such as, Vitamin C content of the dried powder was $0.22 \mathrm{mg}$ per $100 \mathrm{~g}$ of dry matter while fresh fruit has $82 \mathrm{mg}$ to $148 \mathrm{mg}$ per $100 \mathrm{~g}$ dry matter. Also the minerals, $\mathrm{Fe}, \mathrm{K}, \mathrm{Ca}, \mathrm{Mg}$ and $\mathrm{P}$ were detected in higher amounts, than the that of fresh fruit. But only $\mathrm{Na}$ were present in lower amount in dried powder. All the phytochemicals were similar, in raw fruit and dreid powder, except for Anthocyanin, which was absent in dried powder. Potato disc assay also showed statistically similar tumor inhibition ability in raw and dried products.

The phytochemical analysis done for the bark and leaf extracts, revealed that they also have same phytochemicals which present in fruit extracts. 


\section{Chapter 1}

\section{Introduction}

Even people with very good understanding about nutritional aspects of a food and a capability of achieving such food, may not get all the required nutrition and bioactive compounds in adequate amounts, for longer period of time. In that context food supplements are very important to fulfill that gap.

There are different categories of food supplements and in broader aspect, it can be divided into two; Synthetic food supplements (Vitamins, minerals etc.) and natural herbal food supplements and there derivatives. Although synthetic food supplements are capable of addressing the particular gap between required nutrition and achieved nutrition, there are many draw backs such as taking too much of some supplements, such as vitamin A, vitamin D, Vitamin $\mathrm{E}$ and iron can be toxic, using supplements with medicines can cause negative interactions and people with special physiological status such as pregnant and elderly people has to be concern and consult a physician before being using a synthetic food supplements. On the other hand herbal food supplements have many positive benifits over synthetic ones. And the main advantage is that the possibility of being overdose is very minimum as natural compounds are easily removed from the body.

On the other hand herbal supplements have a verity of nutrients, not like the synthetic one and more importantly they have phytochemical and other bioactive compounds which will help / prevent the occurrence of chronic diseases such as cancers, chronic heart diseases, chronic respiratory diseases, hypertension, diabetic mellitus etc.

According to the Global Status Report on Non communicable Diseases 2010, millions of people die due to Non Communicable diseases and the numbers are continuously rising. Situation in Sri Lanka is worse and according to the "cancer incidence data 2001 - 2005" published by WHO, number of cancer incidences as well as the motility rate is being continuously increasing from 1985 to 2005 .

A.muricata (Soursop) is a native plant in Latin American countries such as Peru, Mexico, Cuba etc. and is a small, upright evergreen tree, 5-6 m high, with large, glossy tree with dark green leaves and it produces a dark green, spiny aggregate fruits made up of berries 
fused together with associated flower parts. The oval or heart-shaped and frequently irregular lopsided composite soursop fruit is derived from the fusion of many fruitlets and can weigh more than $4 \mathrm{~kg}$. From a long time ago soursop being consumed as juice blends, ice creams, sherberts, nectars, syrups, shakes, jams, jellies, preserves, yoghurts, and ice creams. (Watson. R., et al ).

There are many research projects that have proved that a special group of bioactive chemicals present in soursop called, Annonaceous acetogenins. (Taylor. L.,et al 2005), which can specifically attack cancer cells and destroy them. There are published clinical studies on this regards. (Zeng, L., et al.1196, Rieser, M. J., et al. 1996, Wu, F. E., et al 1995 , Rieser, M. J., et al 1996 ). Apart from anticancer properties, there are many other medicinal uses of different parts of the soursop tree, fruit, leves, baek and flowers.

Apart from the health benifitial aspects, Soursop is also important in nutritional regards, especially it has important carbohydrates and $100 \mathrm{~g}$ of fresh fruit fulfill $6 \%$ of carbohydrate requirement and 3.55 of the energy requirement. Also it provides $3.8 \%$ of the fiber requiment and the other important minerals such as $\mathrm{Ca}, \mathrm{Mg}, \mathrm{P}, \mathrm{K}$ and $\mathrm{Fe}$. Soursop has very law amount of $\mathrm{Na}$ and therefore contribution to hypertension is minimum. When considering the vitamins it is rich in Ascorbic acid (Vitamin C), Thiamine, Riboflavin and Niacin. Being a fruit with very low fat content is also an additional advantage.

Obviously one would think that the fresh fruit has all the above mentioned advantages while processed supplement such as a capsule with soursop powder doesn't have all these positives.

In this research, Soursop fruit was processed by drying at low temperature, after removing seeds and peel. The reduction of water activity which is key to the microbial activity and enzymatic activity is controlled to achieve the stability of the product.

Preparation of a processed food from Soursop is very important due to many reasons. Main reason is that the production of Soursop is limited to tropical countries where they have high temperature and high humidity. Temperatures below $5{ }^{\circ} \mathrm{C}$ will cause damage to leaves and small branches, and temperatures below $3{ }^{\circ} \mathrm{C}$ can be fatal to the soursop trees. 
(Alias K H B M 2009). It is hard to distribute the fruit to the other part of the world, due to its high perishable nature.

Also the majority of the production is being wasted during the season, in the production sites, due to non availability of sufficient storage, transportation and processing facilities.

There is another aspect of making processed food supplement, using Soursop. It is the nutritional and health aspect. The critical components present in Soursop, phytochemicals, other bioactive components like Annonacious acetogenins and fibers won't store in the body and even if we consumed larger portion of the fruit, excess will be removed from the body with urine. Therefore frequent consumption of fruit is very imported in a nutritional and a health point of view.

Therefore considering those factors, preparation of supplementary food which is easily accessible to everyone and has similar properties to the natural fruit is very important. Accordingly this research has the following objectives;

- To identify best drying temperature for the preparation of Soursop powder.

- To prepare a supplementary food capsule using A.muricata (Soursop) with similar nutritional and medicinal value to the natural fruit.

- To analyze the important bioactive chemical components present in the fruit leaf and bark extracts. 